\title{
Monetary Policy and Multiple Equilibria
}

\author{
Jess Benhabib \\ New York University \\ Stephanie Schmitt-Grohé \\ Board of Governors of the Federal Reserve System \\ Martín Uribe* \\ Board of Governors of the Federal Reserve System
}

July, 1998

\begin{abstract}
In this paper, we study interest rate feedback rules whereby the nominal interest rate is set as an increasing function of the inflation rate and characterize conditions under which such rules generate multiple equilibria. We show that these conditions depend not only on the monetary-fiscal regime (as emphasized in the fiscal theory of the price level) but also on the way in which money is assumed to enter preferences and technology. We analyze this issue in flexible and sticky price environments. We provide a number of examples in which, contrary to what is commonly believed, active monetary policy in combination with a fiscal policy that preserves government solvency gives rise to multiple equilibria and passive monetary policy renders the equilibrium unique.
\end{abstract}

JEL Classification Numbers: E52, E31, E63.

Keywords: Interest rate feedback rules, multiple equilibria, sticky prices.

\footnotetext{
*We would like to thank seminar participants at the University of Chicago, New York University, the Board of Governors, the New York Area Macroeconomics Workshop, and the 1998 NBER Summer Institute for comments. This paper represents the views of the authors and should not be interpreted as reflecting the views of the Board of Governors of the Federal Reserve System or other members of its staff. We thank the C.V. Starr Center of Applied Economics at New York University for technical assistance.
} 


\section{Introduction}

Recent developments in monetary economics have emphasized the link between the degree to which monetary and fiscal policy respond to endogenous variables such as the inflation rate or the stock of public debt and macroeconomic stability. ${ }^{1}$ Perhaps the best-known result in this literature is that if fiscal solvency is preserved under all circumstances, then an active monetary policy, that is, a policy that aggressively fights inflation by raising the nominal interest rate by more than the increase in inflation, stabilizes the real side of the economy by ensuring the uniqueness of equilibrium, whereas a passive monetary policy, that is, a policy that underreacts to inflation by raising the nominal interest rate by less than the observed increase in inflation, destabilizes it by giving rise to expectations-driven fluctuations. In this paper, we show that whether a particular monetary-fiscal regime generates multiple equilibria depends crucially on the way in which money is assumed to enter preferences and technology. In particular, the paper highlights the fact that regardless of the stance of fiscal policy, an active monetary policy does not necessarily bring about the determinacy of equilibrium.

In the context of a flexible-price, money-in-the-utility-function model, we show that the standard result holds in an endowment economy in which consumption and real balances are Edgeworth-complements in preferences in the sense that the marginal utility of consumption is increasing in real balances. However, the opposite result-i.e., uniqueness of the equilibrium occurs under passive monetary policy and multiple equilibria occur under active monetary policy - obtains if consumption and real balances are Edgeworthsubstitutes. More importantly, the opposite result also obtains in an economy in which money enters in the production function, even if real balances and consumption are Edgeworth-complements in preferences.

We also analyze economies with nominal rigidities. Specifically, we study two alternative models of price stickiness: the Rotemberg (1982) model with convex cost of price adjustment and the Calvo (1983) model of staggered price setting. We show that when money enters in the production function, active monetary policy may render the equilibrium indeterminate regardless of the stance of fiscal policy. The finding that the equilibrium may be indeterminate under active monetary when fiscal policy does not guarantee solvency of the government under all circumstances is of particular importance because in economies in which money affects real variables only through aggregate demand, no equilibrium exists locally under this type of monetary-fiscal regime.

The common notion that active monetary policy is tantamount to aggregate stability is further challenged when one does not restrict the analysis to local stability. In sticky-price environments, we find that if money enters in the production function, active monetary policy may give rise to a continuum of equilibria in each of which real variables converge to a deterministic cycle.

Finally, we extend the analysis to feedback rules in which the interest rate depends not only on current inflation but also on past or expected future rates of inflation. We find that the results described above are generally robust to this extension. Backward-looking feedback rules tend to reduce the range of parameter values for which the equilibrium is indeterminate and forward-looking rules tend to increase it.

The remainder of the paper is organized in four sections. Section 2 studies a flexible-price economy. Section 3 characterizes local and periodic equilibria in the Rotemberg sticky-price model. Section 4 extends the results to backward- and forward-looking interest rate feedback rules and to an economy with Calvo-type price staggering. Section 5 concludes.

\section{A flexible-price model}

In this section, we study the determinacy of equilibrium under alternative monetary and fiscal policies in a flexible-price model in which inflation may affect consumption and production as in Calvo (1979). ${ }^{2}$

\footnotetext{
${ }^{1}$ See, for example, Leeper (1991), Sims (1994, 1997), Woodford (1994, 1995, 1996), Clarida, Galí, and Gertler (1997), and Schmitt-Grohé and Uribe (1997).

${ }^{2}$ The monetary-fiscal regimes analyzed by Calvo (1979) are different from those studied in this paper. Calvo focuses on monetary policies whereby the central bank pegs either the money growth rate or the inflation rate in combination with a fiscal policy that specifies zero public debt at all times implying full monetization of primary deficits. By contrast, as will be explained in detail shortly, we analyze interest rate feedback rules in combination with fiscal policies in which the real primary surplus is either constant or proportional to the stock of real government liabilities. Another example of a study of price level determination in a model with money in the production function is Taylor (1977). Like Calvo, Taylor considers monetary policy regimes that are different from those studied in this paper. However, unlike Calvo, Taylor conducts his analysis in the context
} 


\section{The household}

The household's lifetime utility function is given by

$$
U=\int_{0}^{\infty} e^{-r t} u\left(c, m^{n p}\right) d t
$$

where $r>0$ denotes the rate of time preference, $c$ consumption, $m^{n p} \equiv M^{n p} / P$ real balances held for nonproduction purposes, $M^{n p}$ nominal money balances held for non-production purposes, and $P$ the nominal price level. The instant utility function $u(\cdot, \cdot)$ satisfies assumption 1, which implies that $c$ and $m^{n p}$ are normal goods.

Assumption $1 u(\cdot, \cdot)$ is strictly increasing and strictly concave, and satisfies $u_{c c}-u_{c m} u_{c} / u_{m}<0$ and $u_{m m}-u_{c m} u_{m} / u_{c}<0$.

We consider two alternative production technologies: (i) output is produced with real balances held by the household for production purposes, $m^{p} \equiv M^{p} / P$, where $M^{p}$ denotes nominal money balances held for production purposes, and (ii) output is equal to a positive constant. Formally, the production technology, $y\left(m^{p}\right)$, satisfies either assumption 2 or assumption $2^{\prime}$.

Assumption $2 y\left(m^{p}\right)$ is positive, strictly increasing, strictly concave, $\lim _{m^{p} \rightarrow 0} y^{\prime}\left(m^{p}\right)=\infty$, and $\lim _{m^{p} \rightarrow \infty} y^{\prime}\left(m^{p}\right)=0$.

Assumption $\mathbf{2}^{\prime} y\left(m^{p}\right)$ is a positive constant.

In addition to money, the household can hold nominal bonds, $B$, which pay the nominal interest rate $R>0$. Letting $a \equiv\left(M^{n p}+M^{p}+B\right) / P$ denote the household's real financial wealth, $\tau$ real lump-sum taxes, and $\pi \equiv \dot{P} / P$ the inflation rate, the household's instant budget constraint can be written as

$$
\dot{a}=(R-\pi) a-R\left(m^{n p}+m^{p}\right)+y\left(m^{p}\right)-c-\tau .
$$

The household chooses sequences for $c, m^{n p}, m^{p} \geq 0$ and $a$ so as to maximize (1) subject to (2) and the following no-Ponzi-game condition

$$
\lim _{t \rightarrow \infty} e^{-\int_{0}^{t}[R(s)-\pi(s)] d s} a(t) \geq 0,
$$

taking as given $a(0)$ and the time paths of $\tau, R$, and $\pi$. The optimality conditions associated with the household's problem are

$$
\begin{aligned}
u_{c}\left(c, m^{n p}\right) & =\lambda \\
m^{p}\left[y^{\prime}\left(m^{p}\right)-R\right] & =0 \\
\frac{u_{m}\left(c, m^{n p}\right)}{u_{c}\left(c, m^{n p}\right)} & =R \\
\lambda(r+\pi-R) & =\dot{\lambda} \\
\lim _{t \rightarrow \infty} e^{-\int_{0}^{t}[R(s)-\pi(s)] d s} a(t) & =0
\end{aligned}
$$

where $\lambda$ is the Lagrange multiplier associated with the household's instant budget constraint. Assumption 2 together with equation (5) and $R>0$ implies that $m^{p}$ is a strictly decreasing function of $R$ :

$$
m^{p}=m^{p}(R),
$$

with $m^{p^{\prime}} \equiv d m^{p} / d R<0$. Alternatively, assumption $2^{\prime}$, equation (5), and the fact that $R>0$ imply that $m^{p}=m^{p \prime}=0$. Using equation (6) and assumption $1, m^{n p}$ can be expressed as a function of consumption and the nominal interest rate that is increasing in $c$ and decreasing in $R$ :

$$
m^{n p}=m^{n p}(c, R) .
$$

of a non-optimizing framework. 


\section{The government}

We assume that monetary policy takes the form of an interest rate feedback rule whereby the nominal interest rate is set as an increasing function of the inflation rate. Specifically, we assume that

$$
R=\rho(\pi),
$$

where $\rho(\cdot)$ is continuous, non-decreasing, and strictly positive and there exists at least one $\pi^{*}>-r$ such that $\rho\left(\pi^{*}\right)=r+\pi^{*}$. Following Leeper (1991), we refer to monetary policy as active if $\rho^{\prime}>1$ and as passive if $\rho^{\prime}<1$.

The sequential budget constraint of the government is given by $\dot{B}=R B-\dot{M}^{n p}-\dot{M}^{p}-P \tau$, which can be written as

$$
\dot{a}=(R-\pi) a-R\left(m^{n p}+m^{p}\right)-\tau .
$$

Because the nominal value of initial government liabilities, $A(0)$, is predetermined, the initial condition $a(0)$ must satisfy

$$
a(0)=\frac{A(0)}{P(0)} .
$$

We classify fiscal policies into two categories: Ricardian fiscal policies and non-Ricardian ones. Ricardian fiscal policies are those that ensure that the present discounted value of total government liabilities converges to zero - that is, equation (8) is satisfied - under all possible, equilibrium or off-equilibrium, paths of endogenous variables such as the price level, the money supply, inflation, or the nominal interest rate. ${ }^{3}$

Throughout the paper, we restrict attention to one particular Ricardian fiscal policy that takes the form

$$
\tau+R\left(m^{n p}+m^{p}\right)=\alpha a
$$

where the sequence $\alpha$ is chosen arbitrarily by the government subject to the constraint that it is positive and bounded below by $\underline{\alpha}>0$. This policy states that consolidated government revenues, that is, tax revenues plus interest savings from the issuance of money, are always higher than a certain fraction $\underline{\alpha}$ of total government liabilities. A special case of this type of policy is a balanced-budget rule whereby tax revenues are equal to interest payments on the debt, which results when $\alpha=R$ (provided $R$ is bounded away from zero). To see that the fiscal policy given by (14) is Ricardian, let $d \equiv \exp \left[-\int_{0}^{t}(R-\pi) d s\right]$ and $x \equiv d a$. The definition of a Ricardian fiscal policy requires that $x \rightarrow 0$ as $t \rightarrow \infty$. Note that $\dot{x}=d[\dot{a}-(R-\pi) a]$. Using equations (12) and (14), this expression can be written as $\dot{x}=-\alpha x$, which implies that $x$ converges monotonically to zero.

We will also analyze a particular non-Ricardian fiscal policy consisting of an exogenous path for lump-sum taxes

$$
\tau=\bar{\tau}
$$

\section{Equilibrium}

In equilibrium the goods market must clear

$$
c=y\left(m^{p}\right) .
$$

Using equations (9)-(11) and (16) to replace $m^{p}, m^{n p}, R$, and $c$ in equation (4), $\lambda$ can be expressed as a function of $\pi$,

$$
\lambda=\lambda(\pi)
$$

\footnotetext{
${ }^{3}$ Our definition of Ricardian fiscal policy is different from the one given in Woodford (1995). In the first place, Woodford uses the term Ricardian to refer to monetary-fiscal regimes rather than to fiscal regimes alone. Second, according to Woodford, Ricardian regimes are combinations of monetary and fiscal policies that ensure that the present discounted value of public debt, not total government liabilities, converges to zero. Thus, for example, a balanced-budget rule in combination with an interest rate peg is Ricardian according to our definition but not according to Woodford's (see Schmitt-Grohé and Uribe, 1997). Also, Ricardian fiscal policies are not necessarily passive in the sense of Leeper (1991) because they do not guarantee that the real value of public debt remains bounded.
} 
with

$$
\lambda^{\prime}(\pi)=\rho^{\prime}\left[u_{c c} y^{\prime} m^{p^{\prime}}+u_{c m}\left(m_{c}^{n p} y^{\prime} m^{p^{\prime}}+m_{R}^{n p}\right)\right]
$$

where $m_{c}^{n p}$ and $m_{R}^{n p}$ denote the partial derivatives of $m^{n p}$ with respect to $c$ and $R$, respectively. Using this expression, (9)-(11), and (16), equations (7), (8), (12), and (14) can be rewritten as

$$
\begin{gathered}
\lambda^{\prime}(\pi) \dot{\pi}=\lambda(\pi)[r+\pi-\rho(\pi)] \\
\dot{a}=[\rho(\pi)-\pi] a-\rho(\pi)\left[m^{n p}\left(y\left(m^{p}(\rho(\pi))\right), \rho(\pi)\right)+m^{p}(\rho(\pi))\right]-\tau \\
\lim _{t \rightarrow \infty} e^{-\int_{0}^{t}[\rho(\pi)-\pi(s)] d s} a(t)=0 \\
\tau+\rho(\pi)\left[m^{n p}\left(y\left(m^{p}(\rho(\pi))\right), \rho(\pi)\right)+m^{p}(\rho(\pi))\right]=\alpha a
\end{gathered}
$$

Definition 1 (Perfect-foresight equilibrium in the flexible-price economy) In the flexible-price economy, a perfect-foresight equilibrium is a set of sequences $\{\pi, a, \tau\}$ and an initial price level $P(0)>0$ satisfying (13), (19)-(21) and either (15) if fiscal policy is non-Ricardian or (22) if fiscal policy is Ricardian, given $A(0)>0$.

Given an equilibrium sequence for $\pi$, equations (9)-(11), (16), and (17) uniquely determine the equilibrium sequences $\left\{c, m^{n p}, m^{p}, \lambda, R\right\}$. If the equilibrium time path of inflation is unique, then so is the equilibrium real allocation $\left\{c, m^{n p}, m^{p}\right\}$ independently of whether the equilibrium price level is unique. Thus, it is useful to introduce the following terminology:

Definition 2 (Real and Nominal Indeterminacy) The equilibrium displays real indeterminacy if there exists an infinite number of equilibrium sequences $\{\pi\}$. The equilibrium exhibits nominal indeterminacy if for any equilibrium sequence $\{\pi\}$, there exists an infinite number of initial price levels $P(0)>0$ consistent with a perfect-foresight equilibrium.

In the remainder of this section, we restrict the analysis to equilibria in which the inflation rate converges asymptotically to a steady-state value, $\pi^{*}$, which is defined as a constant value of $\pi$ that solves (19), that is, a solution to $r+\pi=\rho(\pi)$. By assumption, $\pi^{*}$ exists and is greater than $-r .^{4}$

Under a Ricardian fiscal policy, the set of equilibrium conditions includes equation (22). Given a sequence $\{\pi\}$ satisfying (19) and an initial price level $P(0)>0$, equations (20) and (22) can be used to construct a pair of sequences $\{a, \tau\}$. Because the fiscal policy is Ricardian, the transversality condition (21) is always satisfied. If instead the fiscal authority follows the non-Ricardian fiscal policy given in (15), combining (13), (20), and (21) yields

$$
\frac{A(0)}{P(0)}=\int_{0}^{\infty} e^{-\int_{0}^{t}[\rho(\pi)-\pi] d s}\left\{\rho(\pi)\left[m^{n p}\left(y\left(m^{p}(\rho(\pi))\right), \rho(\pi)\right)+m^{p}(\rho(\pi))\right]+\bar{\tau}\right\} d s
$$

which given $A(0)>0$ and a sequence for $\pi$ converging to $\pi^{*}$ uniquely determines the initial price level $P(0)$.

The above analysis demonstrates that for the class of monetary-fiscal regimes studied in this paper nominal determinacy depends only on fiscal policy and not on monetary policy - a result that has been emphasized in the recent literature on the fiscal determination of the price level and that we summarize in the following proposition:

Proposition 2.1 If fiscal policy is Ricardian, the equilibrium exhibits nominal indeterminacy. Under the non-Ricardian fiscal policy given by (15), the equilibrium displays nominal determinacy.

\footnotetext{
${ }^{4}$ Note that $\pi^{*}$ may not be unique. In particular, if there exists a steady state $\pi^{*}$ with $\rho^{\prime}\left(\pi^{*}\right)>1$, then since $\rho(\cdot)$ is assumed to be continuous and strictly positive there must also exist a steady state with $\rho^{\prime}<1$.
} 
By contrast, the determinacy of the real allocation is independent of fiscal policy but depends on the stance of monetary policy and on the particular way in which inflation affects production and consumption. To see this, consider solutions to equation (19). If $\lambda^{\prime}\left(\pi^{*}\right)$ and $1-\rho^{\prime}\left(\pi^{*}\right)$ are of opposite sign, any initial inflation rate near the steady state $\pi^{*}$ will give rise to an inflation trajectory that converges to $\pi^{*}$. If, on the other hand, $\lambda^{\prime}\left(\pi^{*}\right)$ and $1-\rho^{\prime}\left(\pi^{*}\right)$ are of the same sign, the only sequence of inflation rates that converges asymptotically to $\pi^{*}$ is one in which the inflation rate is constant and equal to $\pi^{*}$. If $\rho^{\prime}(\pi)=0$ for all $\pi$, then equations (18) and (19) imply that $\lambda$ and $\pi$ are constant. Thus, under a pure interest rate peg the economy exhibits real determinacy.

To understand the conditions under which the model displays real indeterminacy, it is instructive to consider the following two polar cases. Consider first the case in which preferences are separable in consumption and money $\left(u_{c m}=0\right)$ and money is productive (assumption 2 holds). In this case, equation (18) implies that $\lambda^{\prime}=\rho^{\prime} u_{c c} y^{\prime} m^{p^{\prime}}>0$, so that the model displays real indeterminacy if $1-\rho^{\prime}\left(\pi^{*}\right)<0$, that is, if monetary policy is active, and is unique if $1-\rho^{\prime}\left(\pi^{*}\right)>0$, that is, if monetary policy is passive. The intuition behind this result is as follows. Suppose firms initially hold more real balances for production purposes than in the steady state. This will happen only if the nominal interest rate is below its steady-state level. By the interest rate feedback rule, the inflation rate has to be below its steady-state value as well. If monetary policy is active, the decline in the inflation rate is accompanied by a decline in the real interest rate, $R-\pi$, which in turn induces negative consumption growth. Since in equilibrium consumption equals output, and output is an increasing function of real balances, real balances for production purposes will be expected to decline. Therefore, the initial increase in real balances is reversed and the resulting trajectory is consistent with equilibrium. If, on the other hand, monetary policy is passive, the decline in the inflation rate is associated with a rise in the real interest rate, and thus consumption will be expected to grow, moving output and real balances even further away from the steady state. Such a trajectory for real balances would not be remain bounded in a neighborhood around the steady state and thus would not be consistent with an equilibrium in which inflation converges to $\pi^{*}$. This result is summarized in the following proposition.

Proposition 2.2 Suppose preferences are separable in consumption and money $\left(u_{c m}=0\right)$ and money is productive (assumption 2 holds), then if monetary policy is active $\left(\rho^{\prime}\left(\pi^{*}\right)>1\right)$, the equilibrium displays real indeterminacy, whereas if monetary policy is passive $\left(\rho^{\prime}\left(\pi^{*}\right)<1\right)$, then the only perfect-foresight equilibrium in which the real allocation converges to the steady state is the steady state itself.

Consider now the case in which money is not productive, that is, assumption $2^{\prime}$ holds. In this case, equation (18) implies that $\lambda^{\prime}=\rho^{\prime} u_{c m} m_{R}^{n p}$ which is positive if $u_{c m}<0$, that is, if consumption and money are Edgeworth-substitutes, and is negative if $u_{c m}>0$, that is, if consumption and money are complements. Thus the economy displays real indeterminacy if monetary policy is active and consumption and money are substitutes or if monetary policy is passive and consumption and money are complements. ${ }^{5}$ The intuition behind this indeterminacy result is as follows. Consider the case that monetary policy is passive and $u_{c m}>0$. Suppose that real balances for non-productive purposes are increased above their steady-state level. Because the money demand function of the household is decreasing in the nominal interest rate and consumption is constant, it follows that the nominal interest rate has to be below its steady-state level. At the same time, passive monetary policy implies that the decline in the nominal interest rate is associated with an increase in the real interest rate. In response to the increase in the real interest rate agents will lower the growth rate of the marginal utility of consumption. With consumption constant and $u_{c m}>0$, this requires that the growth rate of real balances be negative. Thus real balances will return to their steady level and this trajectory is consistent with equilibrium. The next two propositions summarize these results.

Proposition 2.3 Suppose that money is not productive (assumption $2^{\prime}$ holds) and consumption and money are Edgeworth-substitutes $\left(u_{c m}<0\right)$. Then, if monetary policy is active $\left(\rho^{\prime}\left(\pi^{*}\right)>1\right)$, the real allocation is indeterminate, and if monetary policy is passive $\left(\rho^{\prime}\left(\pi^{*}\right)<1\right)$, then the only perfect-foresight equilibrium in which the real allocation converges to the steady state is the steady state itself.

Proposition 2.4 Suppose that money is not productive (assumption $2^{\prime}$ holds) and consumption and money are Edgeworth-complements $\left(u_{c m}>0\right)$. Then, if monetary policy is passive $\left(\rho^{\prime}\left(\pi^{*}\right)<1\right)$, the real allocation

\footnotetext{
${ }^{5}$ As is well-known, there exists an exact correspondence between the equilibrium conditions of the economy with $y^{\prime}=0$ and $u_{c m}>0$ and those of the cash-in-advance economy with cash and credit goods developed by Lucas and Stokey (1987). Therefore, in the (continuous-time version of the) Lucas-Stokey model, the real allocation is indeterminate under passive monetary policy.
} 
is indeterminate, and if monetary policy is active $\left(\rho^{\prime}\left(\pi^{*}\right)>1\right)$, then the only perfect-foresight equilibrium in which the real allocation converges to the steady state is the steady state itself.

Combining the case of non-productive money (assumption $2^{\prime}$ ) with preferences that are separable in consumption and real balances $\left(u_{c m}=0\right)$ results in the continuous time version of the economy analyzed in Leeper (1991). In this case equation (18) implies that $\lambda$ is constant. It then follows that $\pi, R$ and $m^{n p}$ are also constant, and the only equilibrium real allocation is the steady state. This result differs from that obtained by Leeper who finds that under passive monetary policy the inflation rate is indeterminate. The difference stems from the fact that in Leeper's discrete-time model the nominal interest rate in period $t$ is assumed to be a function of the change in the price level between periods $t-1$ and $t$, whereas in the continuous time model analyzed here, the inflation rate is the right hand side derivative of the price level, so its discrete-time counterpart is better approximated by the change in the price level between periods $t$ and $t+1$. In fact, it is straightforward to show that if in Leeper's discrete-time model the feedback rule is assumed to be forward looking - that is, $R_{t}=\rho\left(P_{t+1} / P_{t}\right)$ - the equilibrium displays real determinacy.

Table 1: Real Indeterminacy in the Flexible-Price Model

\begin{tabular}{|l|c|c|c|c|c|c|}
\hline $\begin{array}{l}\text { Monetary } \\
\text { Policy }\end{array}$ & \multicolumn{3}{|c|}{$\begin{array}{c}\text { Non-productive money } \\
\left(y^{\prime}=0\right)\end{array}$} & \multicolumn{3}{c|}{$\begin{array}{c}\text { Productive money } \\
\left(y^{\prime}>0\right)\end{array}$} \\
\hline & $u_{c m}>0$ & $u_{c m}<0$ & $u_{c m}=0$ & $u_{c m}>0$ & $u_{c m}<0$ & $u_{c m}=0$ \\
\hline Passive $\left(\rho^{\prime}\left(\pi^{*}\right)<1\right)$ & $\mathrm{I}$ & $\mathrm{D}$ & $\mathrm{D}$ & $\mathrm{A}$ & $\mathrm{D}$ & $\mathrm{D}$ \\
\hline Active $\left(\rho^{\prime}\left(\pi^{*}\right)>1\right)$ & $\mathrm{D}$ & $\mathrm{I}$ & $\mathrm{D}$ & $\mathrm{A}$ & $\mathrm{I}$ & $\mathrm{I}$ \\
\hline
\end{tabular}

Note: The notation is: D, determinate; I, indeterminate; A, ambiguous. (Under A the real allocation may be determinate or indeterminate depending on specific parameter values.)

Table 1 summarizes the combinations of preference, technology, and monetary policy specifications under which real indeterminacy arises in the flexible-price model. The second row of the table highlights the main result of this section, namely, that, contrary to what is often asserted, real indeterminacy may arise under active monetary policy. Most existing studies have restricted attention to the case in which money is not productive $\left(y^{\prime}=0\right)$ and money and consumption goods either are complements in preferences or enter the utility function in a separable fashion $\left(u_{c m} \geq 0\right)$. As a result these studies have arrived at the potentially misleading conclusion that an active monetary policy stabilizes the economy by bringing about real determinacy.

We should also note that the results on local uniqueness under active monetary policy should be interpreted with care from a global perspective. As pointed out above, if there exists a steady state $\pi^{*}$ with $\rho^{\prime}\left(\pi^{*}\right)>1$, then since $\rho(\cdot)$ is assumed to be continuous and strictly positive, there must also exist a steady state with $\rho^{\prime}<1$, which can be indeterminate precisely under those assumptions that assure local determinacy at the steady state $\pi^{*}$.

\section{$3 \quad$ A sticky-price model}

In this section, we extend the model developed in the previous section to allow for nominal rigidities. Following Rotemberg (1982), we introduce price stickiness by assuming that the household-firm unit operates in imperfectly competitive product markets and dislikes changing the price it charges for the goods it produces. ${ }^{6}$ Specifically, we assume that there exists a continuum of household-firm units indexed by $j$, each of which produces a differentiated good $Y^{j}$ and faces a demand function $Y^{d} d\left(\frac{P^{j}}{P}\right)$, where $Y^{d}$ denotes the level of aggregate demand, $P^{j}$ the price firm $j$ charges for its output, and $P$ the aggregate price level. Such a demand function can be derived by assuming that households have preferences over a composite good that is produced from differentiated intermediate goods via a Dixit-Stiglitz production function. The function $d(\cdot)$ is assumed to satisfy $d(1)=1$ and $d^{\prime}(1)<-1$. The restriction imposed on $d^{\prime}(1)$ is necessary for the

\footnotetext{
${ }^{6}$ In section 4.2 , we show that the results on local determinacy derived in this section also obtain under Calvo-Yun type price staggering.
} 
firm's problem to be well defined in a symmetric equilibrium. The production of good $j$ is assumed to take real money balances, $m^{p j}$, as the only input

$$
Y^{j}=y\left(m^{p j}\right)
$$

where $y(\cdot)$ satisfies assumption 2 .

The household's lifetime utility function is assumed to be of the form

$$
U^{j}=\int_{0}^{\infty} e^{-r t}\left[u\left(c^{j}, m^{n p j}\right)-\frac{\gamma}{2}\left(\frac{\dot{P}^{j}}{P^{j}}-\pi^{*}\right)^{2}\right] d t
$$

where $c^{j}$ denotes consumption of the composite good by household $j, m^{n p j} \equiv M^{n p j} / P$ denotes real money balances held by household $j$ for non-productive purposes, $M^{n p j}$ denotes nominal money balances, and $\pi^{*}>-r$ denotes the steady-state inflation rate. The utility function $u(\cdot, \cdot)$ satisfies assumption 1 , and the parameter $\gamma$, measuring the degree to which household-firm units dislike to deviate in their price-setting behavior from the long-run level of aggregate price inflation, is positive. The household's instant budget constraint and no-Ponzi-game restriction are

$$
\dot{a}^{j}=(R-\pi) a^{j}-R\left(m^{n p j}+m^{p j}\right)+\frac{P^{j}}{P} y\left(m^{p j}\right)-c^{j}-\tau
$$

and

$$
\lim _{t \rightarrow \infty} e^{-\int_{0}^{t}[R(s)-\pi(s)] d s} a^{j}(t) \geq 0 .
$$

In addition, firms are subject to the constraint that given the price they charge, their sales are demanddetermined

$$
y\left(m^{p j}\right)=Y^{d} d\left(\frac{P^{j}}{P}\right)
$$

The household chooses sequences for $c^{j}, m^{n p j}, m^{p j}, P^{j} \geq 0$, and $a^{j}$ so as to maximize (24) subject to (25)-(27) taking as given $a^{j}(0), P^{j}(0)$, and the time paths of $\tau, R, Y^{d}$, and $P$. The Hamiltonian of the household's optimization problem takes the form

$$
\begin{array}{r}
e^{-r t}\left\{u\left(c^{j}, m^{n p j}\right)-\frac{\gamma}{2}\left(\frac{\dot{P}^{j}}{P^{j}}-\pi^{*}\right)^{2}+\lambda^{j}\left[(R-\pi) a^{j}-R\left(m^{n p j}+m^{p j}\right)\right.\right. \\
\left.\left.+\frac{P^{j}}{P} y\left(m^{p j}\right)-c^{j}-\tau-\dot{a}^{j}\right]+\mu^{j}\left[Y^{d} d\left(\frac{P^{j}}{P}\right)-y\left(m^{p j}\right)\right]\right\} .
\end{array}
$$

The first-order conditions associated with $c^{j}, m^{n p j}, m^{p j}, a^{j}$, and $P^{j}$ and the transversality condition are, respectively,

$$
\begin{gathered}
u_{c}\left(c^{j}, m^{n p j}\right)=\lambda^{j} \\
u_{m}\left(c^{j}, m^{n p j}\right)=\lambda^{j} R \\
\lambda^{j}\left[\frac{P^{j}}{P} y^{\prime}\left(m^{p j}\right)-R\right]=\mu^{j} y^{\prime}\left(m^{p j}\right) \\
\dot{\lambda^{j}}=\lambda^{j}(r+\pi-R)
\end{gathered}
$$




$$
\begin{gathered}
\lambda^{j} \frac{P^{j}}{P} y\left(m^{p j}\right)+\mu^{j} \frac{P^{j}}{P} Y^{d} d^{\prime}\left(\frac{P^{j}}{P}\right)=\gamma r\left(\pi^{j}-\pi^{*}\right)-\gamma \dot{\pi}^{j} \\
\lim _{t \rightarrow \infty} e^{-\int_{0}^{t}[R(s)-\pi(s)] d s} a^{j}(t)=0
\end{gathered}
$$

where $\pi^{j} \equiv \dot{P}^{j} / P^{j}$. Combining equations (28) and (29), the demand for real balances for non-production purposes can be expressed as

$$
m^{n p j}=m^{n p}\left(c^{j}, R\right)
$$

which by assumption 1 is increasing in $c^{j}$ and decreasing in $R$.

\section{Equilibrium}

In a symmetric equilibrium all household-firm units choose identical sequences for consumption, asset holdings, and prices. Thus, $c^{j}=c, m^{p j}=m^{p}, m^{n p j}=m^{n p}, a^{j}=a, P^{j}=P, \lambda^{j}=\lambda, \mu^{j}=\mu$, and $\pi^{j}=\pi$. In addition, the goods markets clear and the no-Ponzi-game restriction holds with equality, that is, equations (8) and (16) are part of the equilibrium conditions. Using (11), (16), and (34), to eliminate $m^{n p}, c$, and $R$ in (28) yields

$$
u_{c}\left(y\left(m^{p}\right), m^{n p}\left(y\left(m^{p}\right), \rho(\pi)\right)\right)=\lambda .
$$

Equation (35) together with assumption 1 implies that $m^{p}$ can be expressed as a function of $\pi$ and $\lambda$ that is decreasing in $\lambda$ and decreasing (increasing) in $\pi$ if $u_{c m}>0(<0)$. Formally, ${ }^{7}$

$$
m^{p}=m^{p}(\lambda, \pi),
$$

where $m_{\lambda}^{p}<0, m_{\pi}^{p} u_{c m}<0$ if $u_{c m} \neq 0$, and $m_{\pi}^{p}=0$ if $u_{c m}=0$. Let $\eta \equiv d^{\prime}(1)<-1$ denote the equilibrium price elasticity of the demand function faced by the individual firm. Using (11), (16), (30), and (36) to eliminate $m^{p}, m^{n p}, \mu, R$, and $c$ from equations (8), (12), (14), (31), and (32) yields

$$
\begin{aligned}
\dot{\lambda} & =\lambda[r+\pi-\rho(\pi)] \\
\gamma \dot{\pi} & =\gamma r\left(\pi-\pi^{*}\right)-y\left(m^{p}(\lambda, \pi)\right) \lambda\left[1+\eta\left(1-\frac{\rho(\pi)}{y^{\prime}\left(m^{p}(\pi, \lambda)\right)}\right)\right] \\
\dot{a} & =[\rho(\pi)-\pi] a-\rho(\pi)\left[m^{n p}\left(y\left(m^{p}(\lambda, \pi)\right), \rho(\pi)\right)+m^{p}(\lambda, \pi)\right]-\tau \\
0 & =\lim _{t \rightarrow \infty} e^{-\int_{0}^{t}[\rho(\pi)-\pi] d s} a(t) \\
\tau & =-\rho(\pi)\left[m^{n p}\left(y\left(m^{p}(\lambda, \pi)\right), \rho(\pi)\right)+m^{p}(\lambda, \pi)\right]+\alpha a
\end{aligned}
$$

Definition 3 (Perfect-foresight equilibrium in the sticky-price economy) In the sticky-price economy, a perfect-foresight equilibrium is a set of sequences $\{\lambda, \pi, \tau, a\}$ satisfying (37)-(40) and either (15) if the fiscal regime is non-Ricardian or (41) if the fiscal regime is Ricardian, given a $(0)$.

Given the equilibrium sequences $\{\lambda, \pi, \tau, a\}$, the corresponding equilibrium sequences $\left\{c, m^{n p}, m^{p}, R\right\}$ are uniquely determined by (11), (16), (34), and (36).

\section{Ricardian fiscal policy}

In this case, the equilibrium conditions include equation (41). Given a pair of sequences $\{\pi, \lambda\}$, equations (39) and (41) can be used to construct time paths for $a$ and $\tau$. Because the fiscal policy is Ricardian, the sequences $\{\pi, a\}$ satisfy the transversality condition (40). Thus any pair of sequences $\{\lambda, \pi\}$ satisfying (37) and (38) can be supported as a perfect-foresight equilibrium.

\footnotetext{
${ }^{7}$ Differentiating equation (35), it follows that $m_{\lambda}^{p}=\left[u_{m m}-\left(u_{m} / u_{c}\right) u_{c m}\right] /\left[y^{\prime}\left(u_{c c} u_{m m}-u_{c m}^{2}\right)\right]$. The concavity of the instant utility function and the normality of consumption imply, respectively, that the denominator of this expression is positive and the numerator negative. Also, $m_{\pi}^{p}=-m_{\lambda}^{p} u_{c m} m_{R}^{n p} \rho^{\prime}$, which is of the opposite sign of $u_{c m}$.
} 
Consider first perfect-foresight equilibria in which $\{\lambda, \pi\}$ converge to a steady-state $\left\{\lambda^{*}, \pi^{*}\right\}$. The steadystate values $\lambda^{*}$ and $\pi^{*}$ are defined as constant values of $\lambda$ and $\pi$ that solve (37) and (38). Thus, $\pi^{*}$ is a solution to $r+\pi^{*}=\rho\left(\pi^{*}\right)$, which by assumption exists but is not necessarily unique. Given a $\pi^{*}$, the steadystate value of real balances for production purposes, $m^{p *}$, is given by the solution to $y^{\prime}\left(m^{p *}\right)=\eta /(1+\eta) R^{*}$, where $R^{*}=\rho\left(\pi^{*}\right)$ is the steady state value of the nominal interest rate. By assumption $2, m^{p *}$ exists and is positive and unique for a given $\pi^{*}$. Finally, $\lambda^{*}$ is given by $\lambda^{*}=u_{c}\left(c^{*}, m^{n p}\left(c^{*}, R^{*}\right)\right)>0$, where $c^{*}=y\left(m^{p *}\right)$ denotes the steady-state level of consumption. In a neighborhood around $\left(\lambda^{*}, \pi^{*}\right)$, the equilibrium paths of $\lambda$ and $\pi$ can be approximated by the solutions to the following linearization of (37) and (38) around $\left\{\lambda^{*}, \pi^{*}\right\}$

$$
\left(\begin{array}{c}
\dot{\lambda} \\
\dot{\pi}
\end{array}\right)=A\left(\begin{array}{c}
\lambda-\lambda^{*} \\
\pi-\pi^{*}
\end{array}\right)
$$

where

$$
\begin{aligned}
A & =\left[\begin{array}{cc}
0 & u_{c}\left(1-\rho^{\prime}\right) \\
A_{21} & A_{22}
\end{array}\right] \\
A_{21} & =-\frac{u_{c} c^{*} \eta R^{*} y^{\prime \prime} m_{\lambda}^{p}}{\gamma y^{\prime 2}}>0 \\
A_{22} & =r+\frac{u_{c} c^{*} \eta}{\gamma}\left[\frac{\rho^{\prime}}{y^{\prime}}-\frac{R^{*}}{{y^{\prime}}^{2}} y^{\prime \prime} m_{\pi}^{p}\right]
\end{aligned}
$$

If at the particular steady state considered monetary policy is passive $\left(\rho^{\prime}\left(\pi^{*}\right)<1\right)$, the determinant of $A$, given by $-A_{21} u_{c}\left(1-\rho^{\prime}\right)$, is negative, implying that $A$ has one positive real root and one negative real root. Since both $\lambda$ and $\pi$ are jump variables, it follows that there exists a neighborhood around the steady state such that for any initial $\lambda(0)$ there exists a $\pi(0)$ in that neighborhood such that the trajectories of $\lambda$ and $\pi$ implied by (42) will converge asymptotically to the steady state. The following proposition summarizes this result.

Proposition 3.1 If fiscal policy is Ricardian and monetary policy is passive $\left(\rho^{\prime}\left(\pi^{*}\right)<1\right)$, then there exists a continuum of perfect-foresight equilibria in which $\pi$ and $\lambda$ converge asymptotically to the steady state $\left(\pi^{*}, \lambda^{*}\right)$.

Under active monetary policy $\left(\rho^{\prime}\left(\pi^{*}\right)>1\right)$ the determinant of $A$ is positive and hence the real parts of its eigenvalues have the same sign. If the trace of $A$, given by $A_{22}$, is negative, then the real parts of the roots are negative, which implies that near the steady state there exists an infinite number of perfect-foresight equilibria converging to the steady state. If, on the other hand, the trace of $A$ is positive, both eigenvalues have positive real parts, and therefore the only perfect-foresight equilibrium converging to the steady state is the steady state itself. We formally state these results in the following proposition.

Proposition 3.2 If fiscal policy is Ricardian and monetary policy is active $\left(\rho^{\prime}\left(\pi^{*}\right)>1\right)$, then, if $A_{22}>0(<$ 0 ), there exists a unique (a continuum of) perfect-foresight equilibria in which $\pi$ and $\lambda$ converge to the steady state $\left(\pi^{*}, \lambda^{*}\right)$.

To illustrate that either of these two cases is possible consider the simple case that the instant utility function is separable in consumption and money and logarithmic in consumption, so that $u_{c} c^{*}=1$. In this case, the trace of $A$ is given by ${ }^{8}$

$$
\operatorname{trace}(A)=r+\frac{(1+\eta) \rho^{\prime}}{\gamma R^{*}}
$$

Let $\bar{\rho}^{\prime} \equiv-\frac{r R^{*} \gamma}{1+\eta}$ denote the value of $\rho^{\prime}$ at which the trace vanishes. Clearly, $\bar{\rho}^{\prime}$ may be greater or less than one. If $\bar{\rho}^{\prime} \leq 1$, then the equilibrium is indeterminate for any active monetary policy. We highlight this result in the following corollary.

\footnotetext{
${ }^{8}$ In deriving this expression we used the facts that when $u_{c m}=0, m_{\pi}^{p}=0$ and that in the steady state $y^{\prime}=R^{*} \eta /(1+\eta)$.
} 
Corollary 1 Suppose fiscal policy is Ricardian and preferences are log-linear in consumption and real balances. If $\bar{\rho}^{\prime} \equiv-\frac{r R^{*} \gamma}{1+\eta}$ is less than or equal to one, then there exists a continuum of perfect-foresight equilibria in which $\pi$ and $\lambda$ converge to the steady state $\left(\pi^{*}, \lambda^{*}\right)$ for any active monetary policy.

On the other hand, if $\bar{\rho}^{\prime}>1$, then for values of $\rho^{\prime} \in\left(1, \bar{\rho}^{\prime}\right)$ the trace of $A$ is positive, and the only equilibrium paths $\{\lambda, \pi\}$ converging to the steady state are ones in which $\lambda$ and $\pi$ are constant and equal to their steady-state values. For values of $\rho^{\prime}>\bar{\rho}^{\prime}$ the trace of $A$ is negative and the perfect-foresight equilibrium is indeterminate. ${ }^{9}$

To facilitate comparison to recent studies on the macroeconomic effects of alternative interest rate feedback rules continue to assume that the instant utility function is log-linear in consumption. In this case, equations (37) and (38) are qualitatively equivalent to the IS and aggregate supply equations arising from a Calvo-type sticky-price model in which money does not enter the production function, like (a continuous time version of) Woodford (1996), Bernanke and Woodford (1997), or Clarida, Galí, and Gertler (1997), with one important exception: in our model the aggregate supply equation features an ambiguous partial derivative of $\dot{\pi}$ with respect to $\pi$ given by $r+\frac{(1+\eta) \rho^{\prime}}{\gamma R^{*}}$ whereas in the models just cited this derivative is unambiguously positive and equal to $r$.

If the partial derivative of $\dot{\pi}$ with respect to $\pi$ is positive, then $A_{22}$ is positive and by propositions 3.1 and 3.2 the equilibrium is locally indeterminate under passive monetary policy and is locally determinate under active monetary policy, that is, in this case our findings coincide with those reported in, for example, Clarida, Galí, and Gertler (1997). On the other hand, if the partial derivative of $\dot{\pi}$ with respect to $\pi$ is negative, that is, $A_{22}<0$, then equilibrium is indeterminate not only under passive but also under active monetary policy. By comparison, in a continuous time version of the sticky-price model just cited, indeterminacy can never obtain under active monetary policy. ${ }^{10}$ This difference in results is important because it calls into question the policy recommendation implicit in the analysis of previous papers that active monetary policy is stabilizing.

\section{Periodic perfect-foresight equilibria}

So far we have restricted attention to perfect-foresight equilibria in which $\{\lambda, \pi\}$ converge asymptotically to $\left\{\lambda^{*}, \pi^{*}\right\}$. We now investigate the existence of perfect-foresight equilibria in which $\lambda$ and $\pi$ converge asymptotically to a deterministic cycle. Consider an economy with preferences given by $u\left(c, m^{n p}\right)=(1-$ $s)^{-1} c^{1-s}+V\left(m^{n p}\right), s>0$; technology given by $y\left(m^{p}\right)=\left(m^{p}\right)^{\alpha}, 0<\alpha<1$; and a smooth interest-rate feedback rule, $\rho(\pi)>0$, which in for $\pi$ in the neighborhood of $\pi^{*}$ takes the form $\rho(\pi)=R^{*}+a\left(\pi+r-R^{*}\right)$, $a>0, R^{*}>0 .{ }^{11}$ Consider the steady state inflation rate $\pi^{*}=R^{*}-r$. In this case the trace of $A$ is given by

$$
\operatorname{trace}(A)=r+\frac{\eta a}{\alpha \gamma}\left(\frac{\eta}{1+\eta} \frac{R^{*}}{\alpha}\right)^{\frac{1-\alpha s}{\alpha-1}}
$$

Let $\bar{a} \equiv \frac{-r \alpha \gamma}{\eta}\left(\frac{\eta}{1+\eta} \frac{R^{*}}{\alpha}\right)^{\frac{1-\alpha s}{\alpha-1}}$ denote the value of $a$ at which the trace of $A$ is equal to zero. Consider parameter configurations for which $\bar{a}>1$. As $a$ crosses $\bar{a}$ from below, the real parts of the two complex roots of $A$ change sign from positive to negative. This is the standard case of a Hopf bifurcation, which implies that generically (i.e., if the system is non-linear), there will exist a family of cycles for $a$ either in a left or in a right neighborhood of $\bar{a} .{ }^{12}$ Furthermore, if the cycle is to the left of $\bar{a}$ where the steady state is unstable (i.e., the bifurcation point is supercritical), the cycle will be attracting. The implication is that if the bifurcation is supercritical, any trajectory $\{\lambda, \pi\}$ that starts out in the neighborhood of $\left\{\lambda^{*}, \pi^{*}\right\}$ will converge to a cycle,

\footnotetext{
${ }^{9}$ In the context of a discrete-time, flexible-price, cash-in-advance economy with cash and credit goods, Schmitt-Grohé and Uribe (1997) obtain a similar result, namely, the perfect-foresight equilibrium is indeterminate for passive and very active monetary policy and is determinate for moderately active policies.

${ }^{10}$ Technically, this follows from the fact that in this case $A_{22}$ is necesarily positive, so that if monetary policy is active, both eigenvalues of the matrix $A$ have positive real parts.

${ }^{11}$ Because a linear rule defined for all possible values of $\pi$ would yield negative nominal interest rates for some $\pi$, we do not require the linear specification to hold globally.

${ }^{12}$ The Hopf Bifurcation Theorem postulates the existence of a family of cycles, which in the pure linear system pile up at the bifurcation value $\bar{a}$ and create a center: any nonlinearity will spread them out to either a left or a right neighborhood of $\bar{a}$. Generically in the non-linear case the amplitude of the cycle varies continuously with $a-\bar{a}$ and is zero at $a=\bar{a}$.
} 
so that the equilibrium is indeterminate. The following proposition provides simple conditions under which a supercritical Hopf bifurcation exists.

Proposition 3.3 Consider an economy with preferences given by $u\left(c, m^{n p}\right)=(1-s)^{-1} c^{1-s}+V\left(m^{n p}\right), s>0$; technology given by $y\left(m^{p}\right)=\left(m^{p}\right)^{\alpha}, 0<\alpha<1$; and monetary policy given by a smooth interest-rate feedback rule, $\rho(\pi)>0$, which for $\pi$ in the neighborhood of $\pi^{*}$ takes the form $\rho(\pi)=R^{*}+a\left(\pi+r-R^{*}\right)$, a $>0$,

$R^{*}>0$. Let fiscal policy be Ricardian and let the parameter configuration satisfy $\bar{a} \equiv \frac{-r \alpha \gamma}{\eta}\left(\frac{\eta}{1+\eta} \frac{R^{*}}{\alpha}\right)^{\frac{1-\alpha s}{\alpha-1}}>1$ and $1<s<1 / \alpha$. Then there exists an infinite number of active monetary policies satisfying a $<\bar{a}$ for each of which the perfect foresight equilibrium is indeterminate and $\pi$ and $\lambda$ converge asymptotically to a deterministic cycle.

Proof: See the appendix.

The implications of the results obtained under sticky prices and Ricardian fiscal policy can be summarized as follows. It is often argued (typically in the context of discrete-time models) that under fiscal policies which guarantee the solvency of the government, a moderately active monetary policy, that is, a policy such that $\rho^{\prime}\left(\pi^{*}\right)>1$ but below a certain threshold, is stabilizing in the sense that it ensures nominal and real determinacy. ${ }^{13}$ However, propositions 3.2 and 3.3 show that even moderately active monetary policies may not eliminate the possibility of real indeterminacy in a sticky-price economy, and corollary 1 gives sufficient conditions for indeterminacy under any active monetary policy. In addition, as noted in section 2 , if the nominal interest rate rule is positive, non-decreasing, and continuous for all $\pi$, the existence of a steady state at which monetary policy is active implies the existence of another steady state at which monetary policy is passive, and which by proposition 3.1 is necessarily indeterminate.

\section{Non-ricardian fiscal policy}

Suppose now that the government follows the non-Ricardian fiscal policy described in equation (15), that is, a fiscal policy whereby the time path of real lump-sum taxes is exogenous. Using (15) to replace $\tau$ in equation (39) yields

$$
\dot{a}=[\rho(\pi)-\pi] a-\rho(\pi)\left[m^{n p}\left(y\left(m^{p}(\lambda, \pi)\right), \rho(\pi)\right)+m^{p}(\lambda, \pi)\right]-\bar{\tau} .
$$

As before, we restrict attention to equilibria in which $\{\lambda, \pi\}$ converge to a steady-state $\left(\lambda^{*}, \pi^{*}\right)$. It is clear from equation (44) that sequences $\{\lambda, \pi\}$ that converge to $\left(\lambda^{*}, \pi^{*}\right)$ will in general be associated with sequences for $a$ that grow asymptotically at the rate $\rho\left(\pi^{*}\right)-\pi^{*}=r>0$, thus violating the transversality condition (40). As a consequence equations (44) and (40) impose restrictions on the set of sequences $\{\lambda, \pi\}$ that are consistent with a perfect-foresight equilibrium of the type we are considering. Specifically, only sequences $\{\lambda, \pi\}$ converging to the steady state $\left(\lambda^{*}, \pi^{*}\right)$ that imply (via equation (44)) a sequence for $a$ that converges to a constant value constitute a perfect-foresight equilibrium. Thus, one can analyze the dynamic properties of the model by restricting attention to a linear approximation of the equilibrium conditions (37), (38), and (44), which can be written as

$$
\left(\begin{array}{l}
\dot{\lambda} \\
\dot{\pi} \\
\dot{a}
\end{array}\right)=\left[\begin{array}{cc}
A & 0 \\
\epsilon & r
\end{array}\right]\left(\begin{array}{l}
\lambda-\lambda^{*} \\
\pi-\pi^{*} \\
a-a^{*}
\end{array}\right)
$$

where $A$ is defined in (42) and $\epsilon$ is a one by two vector whose elements are the steady-state derivatives of $R\left(m^{n p}+m^{p}\right)$ with respect to $\lambda$ and $\pi$.

Since the Jacobian in (45) is quasi-diagonal, its three eigenvalues are given by the two eigenvalues of the matrix $A$ and $r>0$. Because $a$ is the only non-jump variable of the system, there exist multiple equilibria converging to the steady state if and only if both roots of $A$ have negative real parts. Since-as pointed out above $-\rho^{\prime}>1$ is a necessary and sufficient conditions for both eigenvalues of $A$ to be of the same sign, the possibility of multiple equilibrium paths $\{\lambda, \pi\}$ converging asymptotically to the steady-state

\footnotetext{
${ }^{13}$ See for example, Bernanke and Woodford (1997), Clarida, Galí, and Gertler (1997) or Schmitt-Grohé and Uribe (1997).
} 
can only arise under active monetary policy. Under passive monetary policy the matrix $A$ has exactly one negative eigenvalue, therefore, there exists a unique equilibrium converging to the steady state. Finally, if all eigenvalues of $A$ have positive real parts, which will be the case if monetary policy is active and $A_{22}$ is positive, there exists no equilibrium converging to the steady state. These results are summarized in the following propositions

Proposition 3.4 If fiscal policy is non-Ricardian and monetary policy is passive $\left(\rho^{\prime}\left(\pi^{*}\right)<1\right)$, then there exists a unique perfect-foresight equilibrium in which $\{\lambda, \pi\}$ converge asymptotically to the steady state $\left(\pi^{*}, \lambda^{*}\right)$.

Proposition 3.5 If fiscal policy is non-Ricardian and monetary policy is active $\left(\rho^{\prime}\left(\pi^{*}\right)>1\right)$, then if $A_{22}>$ $0(<0)$, there exists no (a continuum of) perfect-foresight equilibria in which $\{\lambda, \pi\}$ converge asymptotically to the steady state $\left(\pi^{*}, \lambda^{*}\right)$.

The result contained in proposition 3.4 is similar to the one obtained in Woodford (1996) in the context of a discrete-time Calvo-type sticky-price model without money in the production function. What distinguishes our findings from previous studies is the result that the equilibrium can be locally indeterminate under nonRicardian fiscal policy (proposition 3.5). As pointed out above, in a continuous-time version of Woodford (1996), the trace of $A$ is positive and equal to $r$, so that at least one eigenvalue of $A$ is always positive. Thus, in such a model indeterminacy can never arise under non-Ricardian fiscal policy.

\section{Periodic perfect-foresight equilibria}

In the case that monetary policy is active and both eigenvalues of $A$ are positive, there may exist bounded equilibria that converge to a stable cycle around the steady state. Note that for the system (37), (38), and (44) the dynamics of $\{\lambda, \pi\}$ are independent of $a$, and thus the analysis of periodic equilibria of the previous section still applies. For example, under the preference and technology specification of the economy described in proposition 3.3, if cycles exist, any initial condition for $(\lambda, \pi)$ in the neighborhood of the steady state will converge to a cycle. To assure that $a$ does not explode, however, we must restrict ourselves to a one dimensional manifold in $\{\lambda, \pi\}$. This follows because while cycles restricted to the $\{\lambda, \pi\}$ plane are attracting, in the three dimensional space the cycle in $\{\lambda, \pi, a\}$ will have only a two dimensional stable manifold: initial values of $\lambda$ and $\pi$ will have to be chosen to assure that the triple $\{\lambda, \pi, a\}$ converges to the cycle and $a$ remains bounded.

Table 2: Real indeterminacy in the Sticky-Price Model

\begin{tabular}{|l|c|c|}
\hline & \multicolumn{2}{|c|}{ Fiscal Policy } \\
\cline { 2 - 3 } Monetary Policy & Ricardian & Non-Ricardian \\
\hline Passive $\left(\rho^{\prime}\left(\pi^{*}\right)<1\right)$ & I & D \\
\hline Active $\left(\rho^{\prime}\left(\pi^{*}\right)>1\right)$ & & \\
$A_{22}<0$ & I & I \\
$A_{22}>0$ & I or D & I or NE \\
\hline
\end{tabular}

Note: The notation is D, determinate; I, indeterminate; NE, no perfect-foresight equilibrium exists.

Table 2 summarizes the results of this section. It shows the combinations of fiscal and monetary policies for which the real allocation is indeterminate in the sticky-price model. The last two rows of the table illustrate a central point of the paper, namely that active monetary policy need not guarantee real determinacy. In fact, in our model the only monetary-fiscal regime that generates real determinacy without any further restrictions on the parameters governing the speed of nominal adjustment is one in which monetary policy is passive. 


\section{Extensions}

\subsection{Backward- and forward-looking feedback rules}

\section{Flexible-price model}

We now analyze a generalization of the interest-rate feedback rule in which the nominal interest rate depends not only on current but also on past or future rates of inflation. Consider first the following backward-looking feedback rule

$$
R=\rho\left(q \pi+(1-q) \pi^{p}\right) ; \quad \rho^{\prime}>0 ; q \in[0,1]
$$

where $\pi^{p}$ is a weighted average of past rates of inflation and is defined as

$$
\pi^{p}=b \int_{-\infty}^{t} \pi e^{b(s-t)} d s ; \quad b>0
$$

Differentiating this expression with respect to time yields

$$
\dot{\pi}^{p}=b\left(\pi-\pi^{p}\right)
$$

The rest of the equilibrium conditions are identical to those obtained in section 2. In particular, we have that

$$
\lambda^{\prime}(R) \dot{R}=\lambda(R)[r+\pi-R]
$$

where

$$
\lambda^{\prime}(R)=\left[u_{c c} y^{\prime} m^{p \prime}+u_{c m}\left(m_{c}^{n p} y^{\prime} m^{p \prime}+m_{R}^{n p}\right)\right]
$$

Using equation (46) to eliminate $\pi$ from (48) and (49) and linearizing around the steady state results in the following system of linear differential equations

$$
\left[\begin{array}{c}
\dot{R} \\
\dot{\pi}^{p}
\end{array}\right]=\left[\begin{array}{cc}
\frac{\lambda}{\lambda^{\prime}}\left(\frac{1}{\rho^{\prime} q}-1\right) & -\frac{\lambda}{\lambda^{\prime}} \frac{(1-q)}{q} \\
b \frac{1}{\rho^{\prime} q} & -\frac{b}{q}
\end{array}\right]\left[\begin{array}{c}
R-R^{*} \\
\pi^{p}-\pi^{*}
\end{array}\right]
$$

Let $J$ denote the Jacobian matrix of this system. Because $R$ is a jump variable and $\pi^{p}$ is predetermined, the real allocation is locally unique if the real parts of the eigenvalues of $J$ have opposite signs, or, equivalently, if the determinant of $J$ is negative. On the other hand, the real allocation is locally indeterminate if both eigenvalues have negative real parts, that is, if the determinant of $J$ is positive and its trace is negative. The determinant and trace of $J$ are given by

$$
\begin{gathered}
\operatorname{det}(J)=\frac{\lambda}{\lambda^{\prime}} \frac{b}{\rho^{\prime} q}\left(\rho^{\prime}-1\right) \\
\operatorname{trace}(J)=\frac{\lambda}{\lambda^{\prime}}\left(\frac{1}{\rho^{\prime} q}-1\right)-\frac{b}{q}
\end{gathered}
$$

As in section 2, consider the two polar cases of money entering only through preferences $\left(y^{\prime}=0\right)$ and money entering only through production $\left(u_{c m}=m_{R}^{n p}=0\right)$. If money enters only through preferences and money and consumption are Edgeworth complements $\left(u_{c m}>0\right)$, then equation (50) implies that $\lambda^{\prime}$ is negative. It follows directly from the above two expressions that the conditions governing the local determinacy of $R$ are identical to those obtained under a purely contemporaneous feedback rule. Namely, the equilibrium is unique under active monetary policy $\left(\rho^{\prime}>1\right)$ and is indeterminate under passive monetary policy $\left(\rho^{\prime}<1\right)$.

When money enters only through production or only through preferences with consumption and money being Edgeworth substitutes, $\lambda^{\prime}$ is positive. Thus, the equilibrium is always locally determinate under passive monetary policy, as was the case under purely contemporaneous feedback rules. However, contrary 
to the case of purely contemporaneous feedback rules, if monetary policy is active, then equilibria in which $R$ converges to its steady state may not exist. To see this, note that in this case the determinant of $J$ is positive, so that the real parts of the roots of $J$ have the same sign as the trace of $J$. However, the trace of $J$ can have either sign. If the trace is positive, then no equilibrium converging to the steady state exists. If it is negative, the equilibrium is indeterminate. For large enough values of $\rho^{\prime}$ the trace of $J$ becomes negative. Thus, highly active monetary policy induces indeterminacy. Furthermore, the larger the emphasis the feedback rule places on contemporaneous inflation ( $q$ close to one) or the lower the weight it assigns to inflation rates observed in the distant past ( $b$ large), the smaller is the minimum value of $\rho^{\prime}$ beyond which the equilibrium becomes indeterminate. In the limit, as $q$ approaches unity or $b$ approaches infinity, the equilibrium becomes indeterminate under every active monetary policy, which is the result obtained under purely contemporaneous feedback rules. On the other hand, as the monetary policy becomes purely backward looking $(q \rightarrow 0)$, no equilibrium in which $R$ converges to its steady state exists under active monetary policy.

We conclude that the more backward-looking the feedback rule is, the less likely it is that active monetary policy renders the equilibrium locally indeterminate. This is not to say, however, that backward-looking behavior in the conduct of monetary policy makes it more likely for the equilibrium to be determinate under active monetary policy. Instead, backward-looking behavior makes a range of active monetary policies for which the equilibrium is indeterminate under purely contemporaneous behavior inconsistent with the existence of equilibria in which the real allocation converges to its steady state.

Consider now a feedback rule whereby the nominal interest rate responds to changes in contemporaneous and expected future inflation. Specifically, assume that the feedback rule takes the form

$$
R=\rho\left(q \pi+(1-q) \pi^{f}\right) ; \quad \rho^{\prime}>0 ; q \in[0,1]
$$

where $\pi^{f}$ is a weighted average of expected future rates of inflation and is defined as

$$
\pi^{f}=d \int_{t}^{\infty} \pi e^{-d(s-t)} d s ; \quad d>0
$$

It is straightforward to show that in this case the system describing the equilibrium dynamics is identical to the one obtained under backward-looking feedback rules with $b$ replaced by $-d$ and $\pi^{p}$ replaced by $\pi^{f}$. Thus, in this case the determinant and trace of the Jacobian become

$$
\begin{gathered}
\operatorname{det}(J)=-\frac{\lambda}{\lambda^{\prime}} \frac{d}{\rho^{\prime} q}\left(\rho^{\prime}-1\right) \\
\operatorname{trace}(J)=\frac{\lambda}{\lambda^{\prime}}\left(\frac{1}{\rho^{\prime} q}-1\right)+\frac{d}{q}
\end{gathered}
$$

Because neither $R$ nor $\pi^{f}$ are predetermined variables, the real allocation is locally unique if both eigenvalues of $J$ have positive real parts and is locally indeterminate if at least one of the roots of $J$ has a negative real part. As in the previous case, the conditions governing the local determinacy of the real allocation are identical to those obtained under purely contemporaneous feedback rules except for one case: if $\lambda^{\prime}<0$, active monetary policy ensures local uniqueness when the feedback rule depends only on current inflation, but may induce indeterminacy if the feedback rule depends on current and future expected inflation. Thus, we conclude that the more forward-looking monetary policy is, the more likely it is that active monetary policy renders the equilibrium locally indeterminate.

It is noteworthy that the dichotomy between nominal and real determinacy that appears when the feedback rule depends only on current inflation survives under backward- and forward-looking policies. If the real allocation is locally unique, then the determinacy of the price level depends exclusively on fiscal policy. As under purely contemporaneous monetary feedback rules, the price level is determinate if fiscal policy is non-Ricardian and is indeterminate if fiscal policy is Ricardian.

\section{Sticky-price model}

The pattern that arises under sticky prices is that if monetary policy is active, the introduction of a backwardlooking component in monetary policy makes determinacy more likely, whereas a forward-looking component 
makes indeterminacy more likely. To facilitate the analysis, we reproduce here the equilibrium conditions for the sticky-price model.

$$
\begin{aligned}
\dot{\lambda} & =\lambda[r+\pi-R] \\
\gamma \dot{\pi} & =\gamma r\left(\pi-\pi^{*}\right)-y\left(m^{p}(\lambda, R)\right) \lambda\left[1+\eta\left(1-\frac{R}{y^{\prime}\left(m^{p}(\lambda, R)\right)}\right)\right] \\
\dot{a} & =[R-\pi] a-R\left[m^{n p}\left(y\left(m^{p}(\lambda, R)\right), R\right)+m^{p}(\lambda, R)\right]-\tau \\
\tau & = \begin{cases}\bar{\tau} & \text { non-Ricardian fiscal policy } \\
\alpha a-R\left[m^{n p}\left(y\left(m^{p}(\lambda, R)\right), R\right)+m^{p}(\lambda, R)\right] & \text { Ricardian fiscal policy }\end{cases} \\
0 & =\lim _{t \rightarrow \infty} e^{-\int_{0}^{t}[R-\pi] d s} a(t)
\end{aligned}
$$

where $m^{p}(\lambda, R)$ results from replacing $\rho(\pi)$ by $R$ in equation (35) and is decreasing in $\lambda$ and increasing (decreasing) in $R$ if $u_{c m}$ is negative (positive).

Consider first a backward-looking feedback rule like the one described in equations (46) and (47). Combining these two equations to eliminate $\pi^{p}$ and linearizing around the steady state yields

$$
\dot{R}=q \rho^{\prime} \dot{\pi}+\rho^{\prime}\left(\pi-\pi^{*}\right)-b\left(R-R^{*}\right) .
$$

Using this expression and linearizing equations (53) and (54), the evolution of $\lambda, \pi$, and $R$ is described by the following system of differential equations:

$$
\left(\begin{array}{c}
\dot{\lambda} \\
\dot{\pi} \\
\dot{R}
\end{array}\right)=A\left(\begin{array}{c}
\lambda-\lambda^{*} \\
\pi-\pi^{*} \\
R-R^{*}
\end{array}\right)
$$

where

$$
A=\left[\begin{array}{ccc}
0 & u_{c} & -u_{c} \\
A_{21} & r & A_{23} \\
\rho^{\prime} q A_{21} & \rho^{\prime}(b+q r) & -b+\rho^{\prime} q A_{23}
\end{array}\right]
$$

and

$$
\begin{aligned}
& A_{21}=-\frac{u_{c} c^{*} \eta R^{*} y^{\prime \prime} m_{\lambda}^{p}}{\gamma{y^{\prime}}^{2}}>0 \\
& A_{23}=\left(\frac{u_{c} c^{*} \eta}{\gamma y^{\prime}}\right)\left(1-\frac{R^{*}}{y^{\prime}} y^{\prime \prime} m_{R}^{p}\right) .
\end{aligned}
$$

Because $\pi^{p}$ is predetermined and $R$ is a function of $\pi$ and $\pi^{p}$, it follows that a linear combination of $\pi-\pi^{*}$ and $R-R^{*}$ is predetermined. In addition, $\lambda$ is a jump variable. Assume first that fiscal policy is Ricardian. Then the local determinacy of the perfect-foresight equilibrium is governed by the eigenvalues of $A$. Specifically, the equilibrium is indeterminate if the real part of at least two roots of $A$ are negative.

Assume that monetary policy is active $\left(\rho^{\prime}>1\right)$. We found in section 3 that under a purely contemporaneous feedback rule, the combination of Ricardian fiscal policy and active monetary policy can render the real allocation either locally determinate or indeterminate, depending on parameter values. By contrast, if the feedback rule is sufficiently backward looking $(q, b \rightarrow 0)$, the equilibrium is always unique. To see this, note that when $\rho^{\prime}>1$ the determinant of $A$, which is given by

$$
\operatorname{Det}(A)=b u_{c} A_{21}\left(1-\rho^{\prime}\right),
$$

is negative. Thus, the number of roots of $A$ with a negative real part is either one or three. If at the same time the trace of $A$ is positive, then the number of roots of $A$ with a negative real part is exactly equal to one. The trace of $A$ is given by

$$
\operatorname{Trace}(A)=r-b+\rho^{\prime} q A_{23} .
$$


Clearly, as $q$ and $b$ approach zero, the trace of $A$ becomes positive.

Assume now that monetary policy is passive $\left(\rho^{\prime}<1\right)$. As shown in 3 , the combination of Ricardian fiscal policy and passive monetary policy always renders the real allocation locally indeterminate under a purely contemporaneous feedback rule. It is straightforward to show that introducing a backward-looking component in the feedback rule cannot bring about local determinacy. To see this, note that if $\rho^{\prime}<1$, the determinant of $A$ is positive, so the number of roots of $A$ with a negative real part can never be exactly equal to one. Unlike the case of purely contemporaneous rules, though, a perfect-foresight equilibrium in which the real allocation converges to its steady state may not exist. This will be the case when all eigenvalues of $A$ have positive real parts. However, if the feedback rule is highly contemporaneous either because $q$ approaches unity or because $b$ approaches infinity, then the equilibrium is always locally indeterminate. To see this, we appeal to the following condition: ${ }^{14}$ The number of roots of $A$ with positive real parts is equal to the number of variations of sign in the scheme:

$$
-1 \quad \operatorname{Trace}(A) \quad-B+\frac{\operatorname{Trace}(A)}{\operatorname{Det}(A)} \quad \operatorname{Det}(A),
$$

where

$$
B=\text { Sum of the principal minors of } A=-u_{c} A_{21}\left(1-q \rho^{\prime}\right)-r b-b \rho^{\prime} A_{23} .
$$

This condition implies that in order for all roots of $A$ to have a positive real part, it is necessary that both the trace of $A$ and $B$ be positive. Consider first the case in which $q \rightarrow 1$. Then the trace of $A$ is positive if and only if $r+\rho^{\prime} A_{23}>0$. But $r+\rho^{\prime} A_{23}>0$ implies that $B$ is negative. To see that the equilibrium is also indeterminate when $b \rightarrow \infty$, note that in this case the trace of $A$ becomes negative. ${ }^{15}$

If fiscal policy is non-Ricardian, then the local determinacy of the perfect-foresight equilibrium is governed by the eigenvalues of a four-by-four Jacobian matrix defining the law of motion of $\lambda, \pi, R$, and $a$. One of the eigenvalues of this matrix is $r>0$ and the other three are those of the matrix $A$. Because $a$ and a combination of $R$ and $\pi$ are predetermined, the equilibrium is locally unique if and only if the Jacobian has exactly two roots with positive real parts. If monetary policy is active, it follows from our previous analysis that the Jacobian matrix has either one or three roots with negative real parts. Thus, local determinacy is impossible. This is the same result as under purely contemporaneous feedback rules. However, if the feedback rule is strongly backward-looking $(b, q \rightarrow 0)$ then no equilibrium in which the real allocation converges to its steady state exists. If monetary policy is passive, the determinant of the Jacobian is positive, implying that there exist either two or zero roots with negative real parts. Thus, as in the case of purely contemporaneous feedback rules, local indeterminacy is impossible. However, unlike the case of contemporaneous rules, under backward-looking monetary policy an equilibrium may not exist.

Finally, consider the case of a forward-looking feedback rule like the one described by equations (51) and (52). We will limit the analysis to the case of Ricardian fiscal policy, leaving the non-Ricardian case to the reader. The law of motion of the vector $(\lambda \pi R)$ is described by a Jacobian matrix that is identical to $A$ with $b$ replaced by $-d$. In addition, the three variables of the system are non-predetermined. Therefore, as long as the Jacobian has at least one root with a negative real part, the perfect-foresight equilibrium is locally indeterminate. Local determinacy requires that all three roots have positive real parts.

Suppose first that monetary policy is active. Under contemporaneous feedback rules, the equilibrium can be locally determinate or indeterminate. The same result obtains under forward-looking rules. However, if the rule is strongly forward-looking $(d, q \rightarrow 0)$ the equilibrium is necessarily locally indeterminate. To see this, note that in this case the trace of the Jacobian tends to $r>0$ and that $B$ tends to $-u_{c} A_{21}<0$, so that the pattern of signs in the scheme $(55)$ is -+++ . If monetary policy is passive, then the determinant is negative, therefore, as in the case of purely contemporaneous rules, the equilibrium is locally indeterminate.

\footnotetext{
${ }^{14}$ This is an application to our special case of a more general theorem due to Routh (see Gantmacher, 1960).

${ }^{15}$ Highly backward-looking policies do not necessarily eliminate the local existence of equilibrium. For example, the equilibrium is indeterminate when the feedback rule places a relatively high weight on inflation rates observed in the distant past $(b \rightarrow 0)$. This is because in this case $B$ is negative.
} 


\subsection{A model with Calvo-Yun-type price staggering}

In this extension, we develop a continuous-time, money-in-the-production function version of Yun's (1996) sticky-price model. ${ }^{16}$ We show that it implies equilibrium conditions that are qualitatively identical to those obtained under the Rotemberg model. Thus, all the results on local determinacy obtained in section 3 carry over to environments with Calvo-Yun price staggering.

\section{Households}

The representative household's lifetime utility function is assumed to be of the form

$$
\int_{0}^{\infty} e^{-r t} u\left(c, m^{n p}\right) d t
$$

where $u(\cdot, \cdot)$ satisfies assumption 1 . The household's instant budget constraint is

$$
\dot{a}=(R-\pi) a-R m^{n p}+x-c-\tau,
$$

where $x$ denotes the household's income measured in units of the composite good, which consists of profits from ownership of shares in firms. The household chooses sequences for $c, m^{n p}$, and $a$ so as to maximize (56) subject to (57) and the no-Ponzi-game borrowing constraint (26), taking as given $a(0)$ and the time paths of $\tau, R, x$, and $\pi$. The first-order conditions associated with the household's optimization problem are (28), (29), and (31) and (26) holding with equality. Combining (28), (29), and (11) yields

$$
c=c(\lambda, \pi) ; \quad c_{\lambda}<0, c_{\pi} u_{c m} \leq 0
$$

\section{Firms}

The production technology and market structure are identical to those assumed in section 3 . The difference with the Rotemberg model stems from the source of nominal rigidities. Following Calvo (1983), suppose that a firm can change the nominal price of the good it produces only when it receives a price-change signal. If the firm does not receive a signal, then its price is assumed to increase automatically at the steady-state inflation rate. The probability of receiving a price-change signal between periods $t$ and $s>t$ is assumed to be given by

$$
1-e^{-\delta(s-t)}, \quad \delta>0
$$

Consider the problem faced by firm $j$ that receives a price-change signal at time $t$. The expected stream of profits associated with a particular price $P^{j}(t)$ is given by

$$
\Pi\left(P^{j}\right)=\int_{t}^{\infty} e^{-\delta(s-t)} e^{-r(s-t)} \lambda(s)\left[\frac{P^{j}(t) e^{\pi^{*}(s-t)}}{P(s)} Y^{d}(s) d\left(\frac{P^{j}(t) e^{\pi^{*}(s-t)}}{P(s)}\right)-R(s) m^{p}(s)^{j}\right] d s .
$$

The expression within square brackets represents profits at time $s$ in the event that the firm has not received a price-change signal between times $t$ and $s$. We ignore the profits corresponding to the events in which the firm receives a price-change signal after time $t$ because they are irrelevant to the firm's current price-setting decision. The present discounted value of the firm's profits are multiplied by $e^{-\delta(s-t)}$, the probability that the price set in $t$ will still be in place at time $s$. The firm discounts profits accruing at time $s$ using the pricing kernel $e^{-r(s-t)} \lambda(s)$ that results from the representative household's optimization problem. This kernel is deterministic because households are assumed to be able to insure against firm-specific risks by holding a portfolio containing shares from all firms in the economy. The firm chooses $P^{j}(t)$ so as to maximize $\Pi\left(P^{j}\right)$, subject to the constraint that sales are demand determined:

$$
y\left(m^{j}\right) \geq Y^{d} d\left(\frac{P^{j}}{P}\right) .
$$

\footnotetext{
${ }^{16}$ Yun's model is a variation of Calvo's (1983) model in which firms are assumed to set prices so as to maximize the present value of profits, instead of following a rule of thumb as assumed by Calvo.
} 
The first-order condition associated with this optimization problem is

$$
0=\int_{t}^{\infty} e^{-(\delta+r) s} \lambda(s) Y^{d}(s) d\left(\frac{P^{j}(t) e^{\pi^{*}(s-t)}}{P(s)}\right)\left[\frac{P^{j}(t) e^{\pi^{*}(s-t)}}{P(s)} \frac{1+\eta}{\eta}-\frac{R(s)}{y^{\prime}\left(m^{p}(s)^{j}\right)}\right] d s,
$$

where, as in section $3, \eta<-1$ denotes the price elasticity of the demand faced by an individual firm and is assumed to be constant. The expression within square brackets is the difference between marginal revenue and marginal cost. Thus, the firm chooses to set today's price so that on average marginal revenue equals marginal cost.

\section{Equilibrium}

We show in the appendix that in equilibrium this first-order condition gives rise to the following aggregate supply equation

$$
\dot{\pi}=\tilde{A}_{21}\left(\lambda-\lambda^{*}\right)+\tilde{A}_{22}\left(\pi-\pi^{*}\right)
$$

where

$$
\begin{aligned}
& \tilde{A}_{21}=(\delta+r) \delta \frac{y^{\prime \prime}}{y^{\prime 2}} c_{\lambda}>0 \\
& \tilde{A}_{22}=r-(\delta+r) \delta\left[\frac{\rho^{\prime}}{y^{\prime}} \frac{\eta}{1+\eta}-\frac{y^{\prime \prime}}{{y^{\prime 2}}^{2}}\left[c_{\pi}+\eta / \delta\right]\right]
\end{aligned}
$$

The remaining equilibrium conditions are identical to those of the Rotemberg sticky-price model developed in section 3. Comparing $\tilde{A}_{21}$ with $A_{21}$ in the aggregate supply function of the Rotemberg model (equation (42)), it follows that the determinants of the Jacobian matrices of the Rotemberg and Calvo models have the same sign. This implies that the results on local indeterminacy under passive monetary policy are identical under both models. Furthermore, by an analysis similar to the one carried out in section 3, it is possible to show that, like $A_{22}, \tilde{A}_{22}$ may take either sign. This is important because it implies that, like the Rotemberg model, the Calvo model can generate local indeterminacy under active monetary policy (regardless of the stance of fiscal policy). This result is entirely due to the assumption that money affects real variables through production. As mentioned earlier, in the Calvo model without money in the production function, the trace of the Jacobian is always positive and equal to $r$.

\section{Conclusion}

In this paper we have shown that the implications of particular interest rate feedback rules for the determinacy of equilibrium depend not only on the fiscal policy regime but also on the structure of preferences and technologies. An important consequence of this finding is that the design of monetary policy should be guided not just by the stance of fiscal policy but also by the knowledge of the deep structural parameters describing preferences and technologies, which significantly complicates the task of the monetary policy maker. 


\section{Appendix}

\section{A. Proof of proposition 3.3}

In the economy under analysis, the equilibrium conditions (37) and (38) take the form

$$
\begin{aligned}
& \frac{\dot{\lambda}}{\bar{\lambda}}=(1-a)\left(\pi-\pi^{*}\right) \\
& \dot{\pi}=r\left(\pi-\pi^{*}\right)-\gamma^{-1} \lambda^{((s-1) / s)}\left[1+\eta\left(1-\frac{R^{*}+a\left(\pi-\pi^{*}\right)}{\alpha \lambda^{((1-\alpha) / \alpha s)}}\right)\right]
\end{aligned}
$$

To prove orbital stability, we use the formula provided by Guckenheimer and Holmes (1983, p. 152), which requires a change of variables and expressing the above system at the Hopf bifurcation as

$$
\left(\begin{array}{c}
\dot{u} \\
\dot{v}
\end{array}\right)=\left[\begin{array}{cc}
0 & -\omega \\
\omega & 0
\end{array}\right]\left(\begin{array}{l}
u \\
v
\end{array}\right)+\left(\begin{array}{c}
f(u, v) \\
g(u, v)
\end{array}\right)
$$

where $\omega$ is a function of the parameters of the model and $f(\cdot, \cdot)$ and $g(\cdot, \cdot)$ satisfy $f(0,0)=g(0,0)=0$ and $f_{i}(0,0)=g_{i}(0,0)=0$ for $i=1,2$; that is, $f(\cdot, \cdot)$ and $g(\cdot, \cdot)$ have no constant or linear terms. The Hopf bifurcation is supercritical (and thus stable cycles exist) if

$$
\begin{aligned}
\kappa \equiv & \left(f_{u u u}+f_{u v v}+g_{u u v}+g_{v v v}\right) \\
& +\frac{1}{\omega}\left[f_{u v}\left(f_{u u}+f_{v v}\right)-g_{u v}\left(g_{u u}+g_{v v}\right)-f_{u u} g_{u u}+f_{v v} g_{v v}\right]<0
\end{aligned}
$$

at $u=v=0$. We obtain this condition by steps.

STEP 1: Let $p=\pi-\pi^{*}$ and $z=\ln \left(\lambda / \lambda^{*}\right)$, where $\lambda^{*}$ denotes the steady-state value of $\lambda$. Then equations (63) and (64) can be written as

$$
\begin{aligned}
& \dot{z}=(1-a) p \\
& \dot{p}=r p+M\left(e^{\beta z}-e^{\sigma z}\right)+N p e^{\beta z}
\end{aligned}
$$

where $\sigma=\frac{s-1}{s}, \beta=\sigma+\frac{\alpha-1}{\alpha s}, M=\gamma^{-1}(1+\eta) \lambda^{* \sigma}<0$, and $N=\gamma^{-1} \eta \alpha^{-1} a \lambda^{* \beta}<0$.

STEP 2: Write the system of differential equations as:

$$
\left[\begin{array}{c}
\dot{z} \\
\dot{p}
\end{array}\right]=\left[\begin{array}{cc}
0 & 1-a \\
M(\beta-\sigma) & 0
\end{array}\right]\left[\begin{array}{l}
z \\
p
\end{array}\right]+\left(\begin{array}{c}
0 \\
G(z, p)
\end{array}\right)
$$

where

$$
G(z, p)=M\left[e^{\beta z}-e^{\sigma z}-(\beta-\sigma) z\right]+p\left(N e^{\beta z}+r\right)
$$

Note that the matrix in the linear part satisfies:

$$
\begin{gathered}
D E T=-M(\beta-\sigma)(1-a) \\
T R A C E=0
\end{gathered}
$$

Assume that $a>1$ and $N=-r$. That is, the parameter configuration corresponds to a Hopf bifurcation. Then letting $\omega=\sqrt{D E T}, \mu=\sqrt{\frac{M(\beta-\sigma)}{a-1}}, v=-z$, and $u=\mu^{-1} p$, the two differential equations become:

$$
\left(\begin{array}{c}
\dot{u} \\
\dot{v}
\end{array}\right)=\left[\begin{array}{cc}
0 & -\omega \\
\omega & 0
\end{array}\right]\left(\begin{array}{l}
u \\
v
\end{array}\right)+\left(\begin{array}{c}
f(u, v) \\
0
\end{array}\right)
$$


where

$$
f(u, v)=\frac{M}{\mu}\left[e^{-\beta v}-e^{-\sigma v}+(\beta-\sigma) v\right]+u\left(N e^{-\beta v}+r\right)
$$

Note that $f(0,0)=f_{u}(0,0)=f_{v}(0,0)=0$. Also, in our formulation $g(\cdot, \cdot)=0$.

STEP 3: The relevant derivatives of $f$ are

$$
\begin{aligned}
f_{v v} & =\frac{M}{\mu}\left[\beta^{2} e^{-\beta v}-\sigma^{2} e^{-\sigma v}\right]+\mu u N \beta^{2} e^{-\beta v} \\
f_{u u} & =0 \\
f_{u u u} & =0 \\
f_{u v} & =-\beta N e^{-\beta v} \\
f_{u v v} & =\beta^{2} N e^{-\beta v}
\end{aligned}
$$

Setting $u=v=0$, it follows that

$$
\kappa=(\beta N)\left[\beta-\mu^{-1} \omega^{-1} M\left(\beta^{2}-\sigma^{2}\right)\right]
$$

Noting that $\mu^{-1} \omega^{-1} M=(\beta-\sigma)^{-1}$ and recalling that $N=-r, \kappa$ reduces to

$$
\kappa=\beta r \sigma
$$

Thus $\kappa$ will be less than zero if and only if

$$
1<s<\frac{1}{\alpha}
$$

\section{B. Derivation of the aggregate supply function in the Calvo-Yun model}

In a symmetric equilibrium all firms that receive a price-change signal will choose the same price. Let this price be denoted by $\mathcal{P}(t)$. Let $p(t) \equiv \mathcal{P}(t) / P(t)$. Then equation (61) can be written as

$$
0=\int_{t}^{\infty} e^{-(\delta+r) s} \lambda(s) Y^{d}(s) d\left(p(t) e^{-\int_{t}^{s}\left[\pi(r)-\pi^{*}\right] d r}\right)\left[\frac{1+\eta}{\eta} p(t) e^{-\int_{t}^{s}\left[\pi(r)-\pi^{*}\right] d r}-\frac{R(s)}{y^{\prime}\left(m^{p}(s)^{j}\right.}\right] d s .
$$

Linearizing this expression around the steady state yields

$$
\begin{aligned}
0= & \int_{t}^{\infty} e^{-(\delta+r) s}\left[\frac{1+\eta}{\eta}\left(\left[p(t)-p^{*}\right]-\int_{t}^{s}\left[\pi(r)-\pi^{*}\right] d r\right)\right. \\
& \left.-\frac{\rho^{\prime}}{y^{\prime}}\left[\pi(s)-\pi^{*}\right]+\frac{R^{*} y^{\prime \prime}}{y^{\prime 2}}\left[m^{p}(s)^{j}-m^{p *}\right]\right] d s .
\end{aligned}
$$

Assume that the consumption good is a composite of the goods produced by each firm. Let the aggregator function be of the Dixit-Stiglitz form with an elasticity of substitution across goods of $\eta$. Then, the price of the composite good is given by

$$
P(t)=\left[\int_{-\infty}^{t} \delta e^{-\delta(t-s)} \mathcal{P}(s)^{1+\eta}\right]^{\frac{1}{1+\eta}} d s
$$

Differentiate this expression to obtain

$$
\pi(t)-\pi^{*}=\frac{\delta}{1+\eta}\left[p(t)^{1+\eta}-1\right],
$$


which after linearizing can be written as

$$
\left[p(t)-p^{*}\right]=\frac{1}{\delta}\left[\pi(t)-\pi^{*}\right]
$$

Using this equation to eliminate $p(t)-p^{*}$ from equation (65) and differentiating the result with respect to $t$ yields

$$
\dot{\pi}=r\left[\pi-\pi^{*}\right]+(\delta+r) \delta \frac{\eta}{1+\eta}\left[-\frac{\rho^{\prime}}{y^{\prime}}\left[\pi-\pi^{*}\right]+\frac{R^{*} y^{\prime \prime}}{{y^{\prime}}^{2}}\left[m^{p j}-m^{p *}\right]\right] .
$$

Using equations (58) and (66) and the fact that in equilibrium $y\left(m^{p j}\right)=c d(p)$ one can express $m^{p j}$ as a function of $\lambda$ and $\pi$, whose linearized form is

$$
m^{p j}-m^{p *}=\frac{1}{y^{\prime}}\left[c_{\lambda}\left(\lambda-\lambda^{*}\right)+\left(c_{\pi}+\eta / \delta\right)\left(\pi-\pi^{*}\right)\right]
$$

Finally, use this expression to eliminate $\left(m^{p j}-m^{p *}\right)$ from (67) to get (62). 


\section{References}

Bernanke, Ben and Michael Woodford "Inflation Forecasts and Monetary Policy" Journal of Money Credit and Banking 29 (1997): 653-684.

Calvo, Guillermo A. "On Models of Money and Perfect Foresight" International Economic Review 29 (February 1979): 83-103.

Calvo, Guillermo A. "Staggered Prices in a Utility-Maximizing Framework" Journal of Monetary Economics 12 (1983): 383-98.

Clarida, Richard, Jordi Galí, and Mark Gertler "Monetary Policy Rules and Macroeconomic Stability: Evidence and Some Theory," May 1997, mimeo, New York University.

Gantmacher, F. R., (1960), The Theory of Matrices, New York: Chelsea.

Guckenheimer, J. and P. Holmes, (1983), Nonlinear Oscillations, Dynamical Systems, and Bifurcations of Vector Fields, New York: Springer-Verlag.

Leeper, Eric "Equilibria under 'Active' and 'Passive' Monetary and Fiscal Policies" Journal of Monetary Economics 27 (1991): 129-147.

Lucas, Robert E. Jr. and Nancy Stokey "Money and interest in a cash-in-advance economy" Econometrica 55 (1987): 491-514.

Rotemberg, Julio J. "Sticky Prices in the United States" Journal of Political Economy 90 (1982): 1187-1211.

Schmitt-Grohé, Stephanie and Martín Uribe "Price-Level Determinacy and Monetary Policy Under a BalancedBudget Requirement," October 1997, mimeo, The Board of Governors of the Federal Reserve System.

Sims, Christopher "A simple model for the study of the determination of the price level and the interaction of monetary and fiscal policy" Economic Theory 4 (1994): 381-399.

Sims, Christopher "Fiscal foundations of price stability in open economies," September 1997, mimeo, Yale University.

Taylor, John B. "Conditions for Unique Solutions in Stochastic Macroeconomic Models with Rational Expectations" Econometrica 45 (1977): 1377-1385.

Woodford, Michael "Monetary policy and price level determinacy in a cash-in-advance economy" Economic Theory 4 (1994): 345-380.

Woodford, Michael "Price-level determinacy without control of the monetary aggregate" Carnegie-Rochester Conference Series on Public Policy 43 (1995): 1-46.

Woodford, Michael "Control of Public Debt: a requirement for price stability," July 1996, NBER Working Paper \#5684.

Yun, Tack "Nominal Price Rigidity, Money Supply Endogeneity, and Business Cycles" Journal of Monetary Economics 37 (1996): 345-370. 